\title{
Accelerometer Based Measurement for the Mapping of Neck Surface Vibrations During Vocalized Speech
}

\author{
Mark Nolan \\ Technological University Dublin, mark.nolan@tudublin.ie \\ Brian Madden \\ Technological University Dublin, brian.madden@tudublin.ie \\ Edward Burke \\ Technological University Dublin, ted.burke@tudubln.ie
}

Follow this and additional works at: https://arrow.tudublin.ie/teapotcon

Part of the Biomedical Devices and Instrumentation Commons

\section{Recommended Citation \\ Nolan, Mark, Madden, Brian, Burke, Edward: Accelerometer Based Measurement for the Mapping of Neck Surface Vibrations During Vocalized Speech. Engineering in Medicine and Biology Society, 2009, EMBC 2009, Annual Internation Conference of the IEEE}

This Conference Paper is brought to you for free and open access by the tPOT: People Oriented Technology at ARROW@TU Dublin. It has been accepted for inclusion in Conference Papers by an authorized administrator of ARROW@TU Dublin. For more information, please contact arrow.admin@tudublin.ie, aisling.coyne@tudublin.ie,gerard.connolly@tudublin.ie. Funder: DIT Abbest

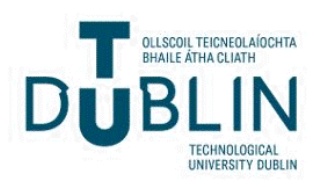




\title{
Accelerometer Based Measurement for the Mapping of Neck Surface Vibrations During Vocalized Speech
}

\author{
Mark Nolan, Brian Madden, and Edward Burke
}

\begin{abstract}
This paper presents a detailed study of the vibrations on the surface of the neck during a vocalization of predefined fundamental frequency and intensity. This study was carried out as part of a wider investigation into the use of laryngeal vibrations as a channel of communication. Another potential application of this study is in identifying a suitable location for a hands-free electro-larynx for laryngectomees.

An analog accelerometer, with dimensions $5 \times 5 \times 1.6 \mathrm{~mm}$ and of mass $80 \mathrm{mg}$, was used to perform the measurements. It was connected to a 12-bit analog-to-digital converter via single strands of insulated wire with a diameter of $100 \mu \mathrm{m}$. The resulting low inertia of the measuring device minimized the effect of the measuring device on the phenomenon under investigation. The analog-to-digital converter simultaneously sampled the accelerometer output and a pre-amplified audio signal from a microphone.
\end{abstract}

This preliminary study was carried out on two able-bodied male subjects. Measurements were taken from forty-five preselected locations on the neck. Each subject made the vowel sound /i/ (long ' $e$ ') at three different fundamental frequencies, $150 \mathrm{~Hz}, 200 \mathrm{~Hz}$ and $250 \mathrm{~Hz}$. Once the vocal pitch and intensity matched pre-defined target values, a $200 \mathrm{~ms}$ recording was captured by a virtual instrument designed in LabVIEW.

A detailed map of skin surface vibration amplitude during vocalization is presented and suitable locations for laryngeal vibration measurement are identified. Further more, detailed analysis of the time varying acceleration function at various measurement positions reveals a rich and complex source of information. Novel visualizations of these signals are presented.

\section{INTRODUCTION}

A CCELEROMETER recordings of neck skin vibrations, have been found to be closely related to vocalizations as recorded using a microphone [1]. Previous studies have used accelerometers to measure subtle body movements emanating from the throat [2] and also to give a general mapping of the skin surface vibrations of the neck and thorax region during sleep [3]. The goal of this research is to provide a detailed study of the vibrations on the surface of the neck during a vocalization of a predefined fundamental frequency and intensity.

The terms fundamental frequency and pitch often refer to subtly different quantities (actual and perceived fundamental frequency respectively). Here however, the term pitch refers

Manuscript submitted April 23, 2009. All authors are members of the TeaPOT research group and belong to the School of Electrical Engineering Systems, Dublin Institute of Technology, Kevin Street, Dublin 8, Ireland.

Mark Nolan and Brian Madden are post-graduate research students. (phone: +353-1-4027980; e-mail: mark.nolan@ dit.ie).

Edward Burke is a lecturer in the School of Electrical Engineering Systems. (phone: +353-1-4024991; e-mail: ted.burke@ dit.ie). to fundamental frequency of phonation. The range of voice pitch varies substantially from one person to another. However, the range for a man usually lies within the interval $50-250 \mathrm{~Hz}$, while that for a woman usually lies within the interval $120-500 \mathrm{~Hz}$ [4, p.114][5].

An initial aim of this study was to identify suitable location(s) for the positioning of a hands-free electro-larynx. Since removal of the larynx has an enormous physical structural impact on the anatomy of the throat, investigation of vibration patterns in able-bodied subjects can provide only limited insight into what may occur in the case of a laryngectomee. This aim was therefore a speculative or exploratory one. Another aim of this study, to which we now attach greater importance, is the use of laryngeal vibrations as a channel of communication and control.

\section{A. Electro-Larynx}

The electro-larynx is a device which is typically used by people who have undergone a laryngectomy (removal of the larynx). It is pressed against the skin under the mandible and uses a mechanical vibration to simulate the work of the larynx [6]. It produces an intelligible, monotonic, voice-like sound. By its nature the device is indiscreet and highly obtrusive which leads to users feeling self-conscious and uncomfortable when operating the device [7].

A goal of this research was to discover whether the ideal location for the electro-larynx is in fact under the mandible or if there is a particular area of the neck from which vibrations, emanating from the larynx, are more intense.

It is important to note that, by recording the vibrations on the surface of the neck during vocalized speech, it was hoped but not assumed that some insight would be gained into the propagation of vibrations traveling in the opposite direction (emanating from an electro-larynx).

\section{B. Control using Laryngeal Vibrations}

A previous related study showed that laryngeal vibrations measured using an accelerometer could be harnessed as a channel of communication, facilitating play and creative expression [8]. That study applied this concept to assist children with physical disabilities to engage with toys and music-making activities to which they would otherwise have limited access.

In that application it was decided that the accelerometer was to be positioned on the suprasternal notch. However, some trial users reported a feeling of discomfort with having the measuring accelerometer module placed on this sensitive 
area of the throat. A desirable outcome of this research would be to find a point with comparable, if not better, vibratory characteristics so as to relocate the measurement module.

\section{MAterials AND PROCEDURES}

\section{A. Materials}

To perform a study on skin vibrations using an accelerometer, it is desirable that the device used be as small and light as possible in order to minimize the potential for the sensor itself to affect the recordings. For this reason, the accelerometer selected for this study was the STMicroelectronics LIS3L02AL. It is a 3 -axis, $\pm 2 \mathrm{~g}$, analog accelerometer, capable of measuring accelerations over a bandwidth of $1.5 \mathrm{kHz}$ for all axes. It has external dimensions of $5 \times 5 \times 1.6 \mathrm{~mm}$, a mass of $80 \mathrm{mg}$, and requires just five wires connected to it to measure acceleration in all of the three axes. Single strands of $100 \mu \mathrm{m}$ diameter wire were used to ensure that the inertia of the measuring device was minimized so that the vibration of the skin was not greatly affected and also that erroneous results which could arise from movement of the subject would be reduced. A block diagram for the recording system is shown in Fig. 1.

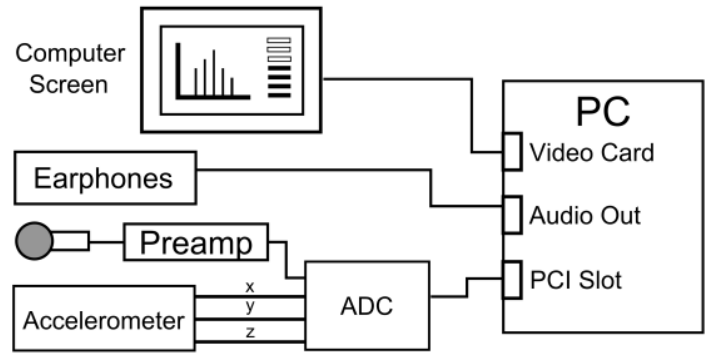

Fig. 1. Block diagram of recording system.

A combined microphone and preamplifier (Maplin $\mathrm{KJ} 44 \mathrm{X}$ ) was used to record the vocalization audio signals. To ensure synchronized sampling of all signals, the microphone and accelerometer were both connected to a National Instruments 6023E 12-bit analog-to-digital converter (ADC). The ADC was set to a sampling frequency of $22.05 \mathrm{kHz}$ on all channels.

Before testing, the pre-amplified microphone was calibrated using a Brüel \& Kjær 2231 Sound Level Meter, at a distance of $15 \mathrm{~cm}$ from a constant audio signal source. The audio intensity was adjusted and the output voltage from the microphone preamplifier was compared with the corresponding recorded Sound Pressure Level (SPL).

A virtual instrument (VI) was created in LabVIEW which streamed in the data from the microphone and the three accelerometer axes through the ADC. The incoming data stream was broken into $200 \mathrm{~ms}$ windows. The sound intensity and fundamental frequency of each window was estimated. The VI gave a visual display of these calculated values and this feedback was updated with each analysis.

After testing, the data was accumulated in MATLAB.
Using equations (1), (2) and (3), the average magnitude of acceleration was calculated for the window of $200 \mathrm{~ms}$ at each point. This result does not represent the 3-dimensional characteristics of the vibrations on the surface of the neck, however, for the positioning of a communication sensor, as primarily envisaged in this paper, this calculation provides adequate interpretation of the data.

$\overrightarrow{a_{p n}}=x_{p n} \vec{i}+y_{p n} \vec{j}+z_{p n} \vec{k}$

$\left|\overrightarrow{a_{p n}}\right|=\sqrt{x_{p n}^{2}+y_{p n}^{2}+z_{p n}^{2}}$

$\left|\overrightarrow{a_{p}}\right|=\frac{\sum_{n=0}^{N-1}\left|\overrightarrow{a_{p n}}\right|}{N}$

Where $p$ is a point on the neck, $n$ is the sample number.

\section{B. Procedure}

The study was performed on two able-bodied male subjects who gave informed consent. The experimental procedure was as follows:

1) The subject's neck dimensions were measured and a personalized grid of the neck was calculated based the grid shown in Fig.2. This grid uses the chin, each angle of the mandible, the hyoid bone, the thyroid cartilage, the cricoid cartilage, the sternal head and the points where the sternocleidomastoideus meets the clavicle as reference points (blue markers). The points illustrated by green markers were calculated by dividing the distance between the reference points using the percentage ratios as shown. Utilizing both of these sets of points the remaining area was divided up (red markers) so that the final result was a grid consisting of forty-five vibration measurement locations.

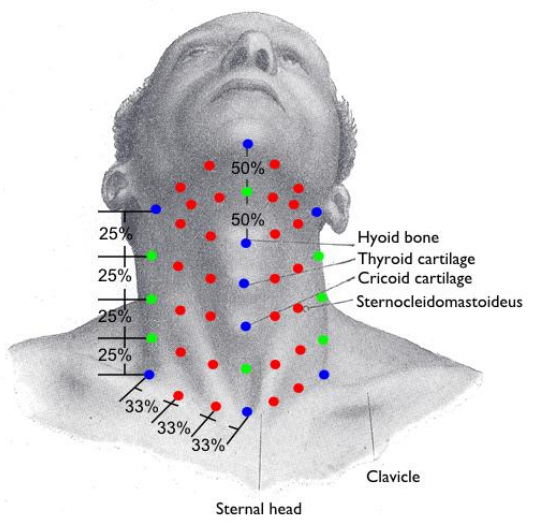

Fig. 2. Diagram showing the accelerometer measuring points [9].

2) To keep the subject's posture constant during testing, his forehead was supported in a head rest, Fig. 3. The angle of the head was set by locating the anterior triangle [9, Ch.6 3a. 3] of the neck and maintaining the angle between the mandible and the line that travels along the sternocleidomastoideus at $100^{\circ}$. The height of the subject's seat was adjusted until this angle was achieved. The microphone was then positioned $15 \mathrm{~cm}$ 
away from the subject's mouth, Fig. 3.
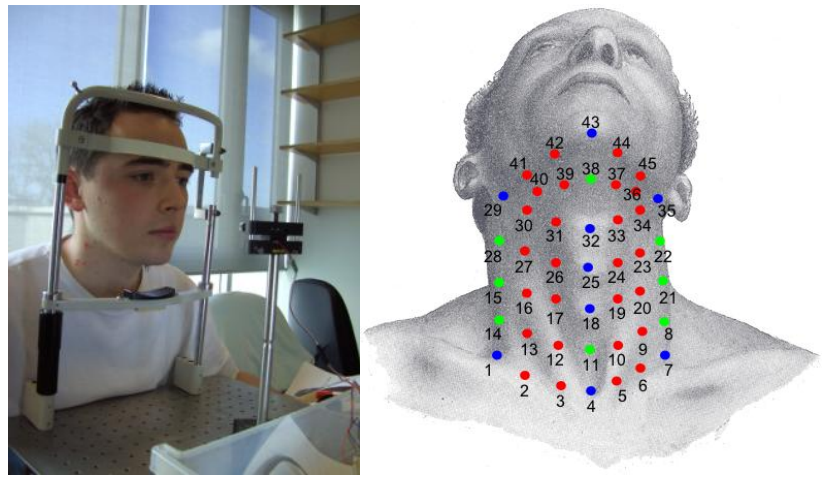

Fig. 3. Picture and diagram showing the experimental setup and accelerometer measuring points.

3) The accelerometer node was then positioned on the first point in the grid, Fig. 3, and the subject was asked to make the vowel sound /i/ (long e) at three different fundamental frequencies, $150 \mathrm{~Hz}, 200 \mathrm{~Hz}$ and $250 \mathrm{~Hz}$, and at a SPL of $70.8 \mathrm{~dB}(0.001 \mathrm{~V})$.

4) Utilizing the live visual display of fundamental frequency and sound intensity, the subject was able to adjust their vocal sound. When their voice reached the desired values, within a 5\% tolerance, the $200 \mathrm{~ms}$ window of data from the audio and the vibrations, at that point on the neck, were recorded.

5) The accelerometer was moved to the next point in the grid and the procedure repeated from step 3 .

\section{RESULTS}

The vibration magnitude values for all measurement points on subject A are listed in tables I, II, and III for each frequency. The same values are represented graphically in Fig. 4, 5, and 6. Both the size and color of each dot represents the average magnitude of acceleration at that point. However the dot color mapping is normalized for each graph, while the dot size scale is constant across all graphs.

The results from Subject B are not shown in this paper. However they were found to be largely similar to the results shown below.

TABLE I MAGNITUDE OF ACCELERATION AT 150Hz

\begin{tabular}{|c|c|c|c|c|c|c|c|}
\hline Pos. ${ }^{a}$ & MAG. ${ }^{b}$ & Pos. ${ }^{a}$ & MAG. ${ }^{b}$ & Pos. ${ }^{a}$ & MAG. $^{\text {b }}$ & Pos. ${ }^{\mathrm{a}}$ & MAG. ${ }^{b}$ \\
\hline 1 & 0.249 & 13 & 0.400 & 25 & 0.790 & 37 & 0.424 \\
\hline 2 & 0.549 & 14 & 0.223 & 26 & 1.350 & 38 & 0.262 \\
\hline 3 & 0.823 & 15 & 0.239 & 27 & 1.320 & 39 & 0.377 \\
\hline 4 & 0.778 & 16 & 0.302 & 28 & 0.576 & 40 & 0.488 \\
\hline 5 & 0.781 & 17 & 0.754 & 29 & 0.314 & 41 & 0.249 \\
\hline 6 & 0.318 & 18 & 1.024 & 30 & 1.000 & 42 & 0.214 \\
\hline 7 & 0.132 & 19 & 0.605 & 31 & 1.036 & 43 & 0.310 \\
\hline 8 & 0.144 & 20 & 0.405 & 32 & 0.658 & 44 & 0.169 \\
\hline 9 & 0.321 & 21 & 0.190 & 33 & 0.794 & 45 & 0.206 \\
\hline 10 & 0.819 & 22 & 0.557 & 34 & 0.914 & & \\
\hline 11 & 1.175 & 23 & 1.132 & 35 & 0.243 & & \\
\hline 12 & 1.208 & 24 & 1.372 & 36 & 0.486 & & \\
\hline
\end{tabular}

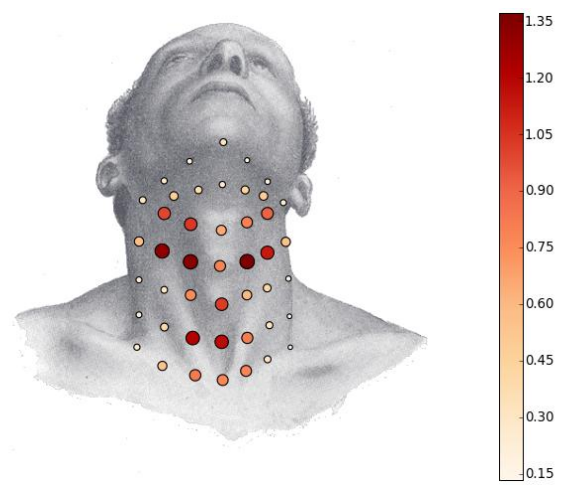

Fig. 4. Diagram showing the variation in average magnitude $\left[\mathrm{m} / \mathrm{s}^{2}\right]$ of acceleration over the measurement grid at $150 \mathrm{~Hz}$ [9, Fig. 1195].

TABLE II

MAGNITUDE OF ACCELERATION AT 200Hz

\begin{tabular}{lccccccc}
\hline \hline Pos. $^{\mathrm{a}}$ & MAG. $^{\mathrm{b}}$ & Pos. $^{\mathrm{a}}$ & MAG. $^{\mathrm{b}}$ & Pos. $^{\mathrm{a}}$ & MAG. $^{\mathrm{b}}$ & Pos. $^{\mathrm{a}}$ & MAG. $^{\mathrm{b}}$ \\
\hline 1 & 0.199 & 13 & 0.372 & 25 & 0.503 & 37 & 0.361 \\
2 & 0.396 & 14 & 0.232 & 26 & 1.064 & 38 & 0.231 \\
3 & 0.615 & 15 & 0.161 & 27 & 1.587 & 39 & 0.376 \\
4 & 0.451 & 16 & 0.299 & 28 & 0.605 & 40 & 0.595 \\
5 & 0.539 & 17 & 0.735 & 29 & 0.108 & 41 & 0.205 \\
6 & 0.196 & 18 & 0.642 & 30 & 1.045 & 42 & 0.199 \\
7 & 0.102 & 19 & 0.581 & 31 & 1.002 & 43 & 0.224 \\
8 & 0.107 & 20 & 0.293 & 32 & 0.635 & 44 & 0.157 \\
9 & 0.214 & 21 & 0.122 & 33 & 0.713 & 45 & 0.209 \\
10 & 0.442 & 22 & 0.627 & 34 & 0.928 & & \\
11 & 0.626 & 23 & 1.178 & 35 & 0.101 & & \\
12 & 0.749 & 24 & 1.307 & 36 & 0.530 & & \\
\hline \hline
\end{tabular}

${ }^{\mathrm{a}}$ Position of accelerometer

${ }^{\mathrm{b}}$ Average magnitude of acceleration over $200 \mathrm{~ms}\left[\mathrm{~m} / \mathrm{s}^{2}\right]$

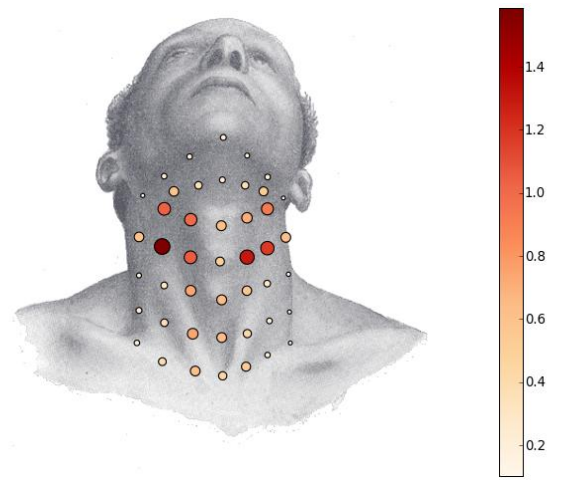

Fig. 5. Diagram showing the variation in average magnitude $\left[\mathrm{m} / \mathrm{s}^{2}\right]$ of acceleration over the measurement grid at $200 \mathrm{~Hz}$ [9, Fig. 1195].

TABLE III

MAGNITUDE OF ACCELERATION AT $250 \mathrm{~Hz}$

\begin{tabular}{|c|c|c|c|c|c|c|c|}
\hline Pos. ${ }^{a}$ & MAG. $^{\text {b }}$ & Pos. ${ }^{a}$ & MAG. $^{\text {b }}$ & Pos. ${ }^{a}$ & MAG. $^{b}$ & Pos. ${ }^{a}$ & MAG. ${ }^{b}$ \\
\hline 1 & 0.149 & 13 & 0.230 & 25 & 0.507 & 37 & 0.434 \\
\hline 2 & 0.227 & 14 & 0.139 & 26 & 1.137 & 38 & 0.246 \\
\hline 3 & 0.451 & 15 & 0.102 & 27 & 1.927 & 39 & 0.308 \\
\hline 4 & 0.443 & 16 & 0.244 & 28 & 0.556 & 40 & 0.485 \\
\hline 5 & 0.352 & 17 & 0.632 & 29 & 0.235 & 41 & 0.212 \\
\hline 6 & 0.105 & 18 & 0.524 & 30 & 1.002 & 42 & 0.165 \\
\hline 7 & 0.074 & 19 & 0.469 & 31 & 0.942 & 43 & 0.182 \\
\hline 8 & 0.077 & 20 & 0.303 & 32 & 0.437 & 44 & 0.136 \\
\hline 9 & 0.130 & 21 & 0.125 & 33 & 0.674 & 45 & 0.171 \\
\hline 10 & 0.337 & 22 & 0.522 & 34 & 0.724 & & \\
\hline 11 & 0.579 & 23 & 1.151 & 35 & 0.237 & & \\
\hline 12 & 0.513 & 24 & 1.378 & 36 & 0.488 & & \\
\hline
\end{tabular}




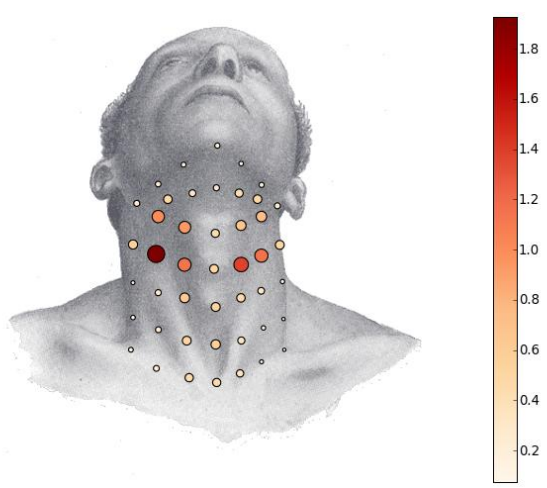

Fig. 6. Diagram showing the variation in average magnitude $\left[\mathrm{m} / \mathrm{s}^{2}\right]$ of acceleration over the measurement grid at 250Hz. [9, Fig. 1195].

In addition to the expected vibration magnitude results as shown in the previous diagrams, what has emerged from the 3-D skin surface acceleration recording is an interesting and decidedly variable pattern of 3-D oscillatory motion at each of the measurement points. Sample acceleration trajectories for two particular points are shown in Fig. 7, 8. The low amplitude of the measured vibrations resulted in the clearly visible quantization of data points in this figure.
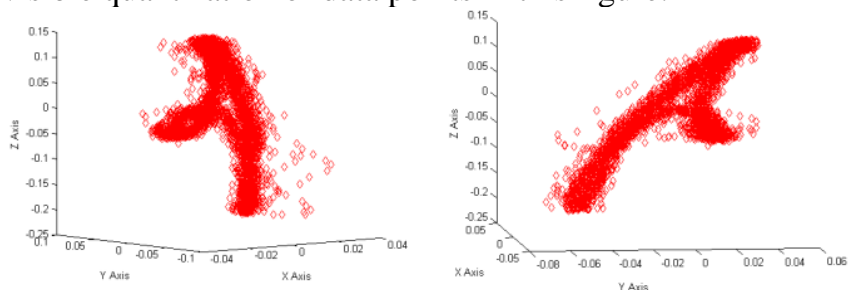

Fig. 7. 3-D Graphs showing the Acceleration Trajectory at $150 \mathrm{~Hz}$ for measurement point 11 from different angles.
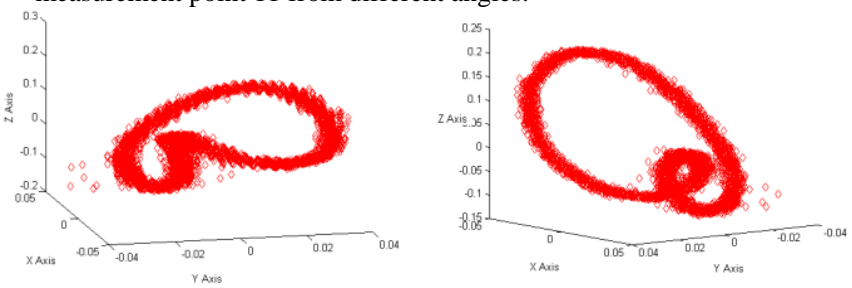

Fig. 8. 3-D Graphs showing the Acceleration Trajectory at $150 \mathrm{~Hz}$ for measurement point 27 from different angles.

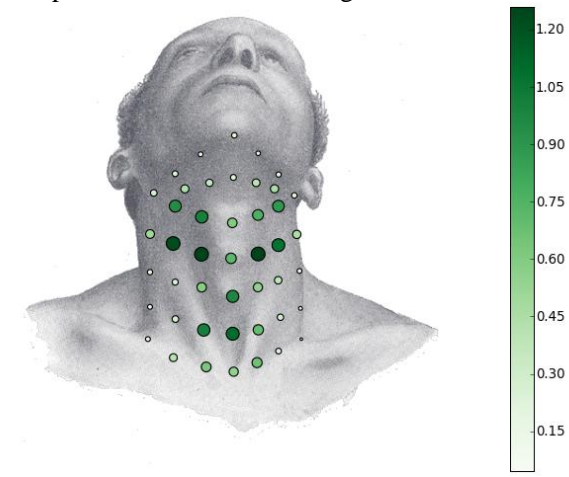

Fig. 9. Diagram showing the average magnitude of acceleration $\left[\mathrm{m} / \mathrm{s}^{2}\right]$ Normal to the skin surface at $150 \mathrm{~Hz}$. Modified from [9, Fig. 1195].

Fig. 9 and Fig. 10 illustrate the difference between the normal and tangential acceleration trajectories. It can be seen that while certain points on the neck typically consist of vibration which is normal to the surface of the skin, there are other points which have significant tangential components.

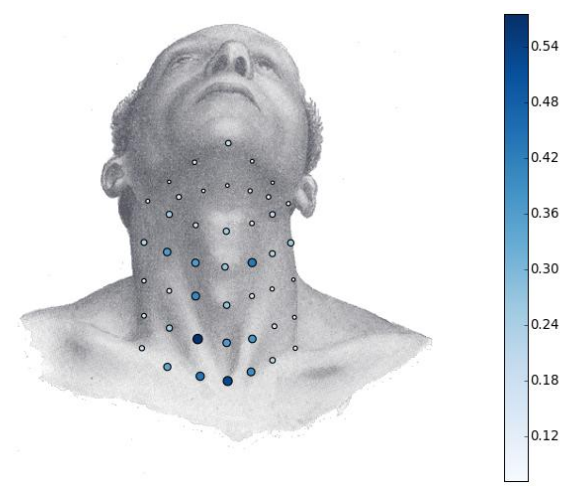

Fig. 10. Diagram showing the average magnitude of acceleration $\left[\mathrm{m} / \mathrm{s}^{2}\right]$ tangential to the skin surface at 150Hz. Modified from [9, Fig. 1195].

\section{CONCLUSIONS}

The variation in vibration amplitude over the region of investigation is largely consistent with expectations. The average magnitude of acceleration tends to be greatest on and in the immediate vicinity of the larynx. It decreases with greater distance from the larynx, but the rate of that decrease is dependent upon the direction. It can be seen that at $150 \mathrm{~Hz}$ (Fig.4), there are significantly more vibrations at the base of the neck compared to those at $250 \mathrm{~Hz}$ (Fig. 6).

The vibrations measured on the mandible are minimal for all frequencies. This indicates that the measured vibrations on the surface of the skin are not suitable to simulate the characteristics of the electro-larynx as applied under pressure to a single point on the neck.

The 3-D acceleration plots reveal a complex pattern of oscillatory motion at the skin surface due to vocalization which may have interesting applications. However, the authors believe that, pending thorough investigation, these trajectories should be treated with some caution. We speculate this is due to sensitivity of sensor placement rather than asymmetrical vibration.

\section{REFERENCES}

[1] J. G. Svec, I. R. Titze, and P. S. Popolo, "Estimation of sound pressure levels of voiced speech from skin vibration of the neck," J. Acoust. Soc. Am. Volume 117, Issue 3, pp. 1386-1394., 2005.

[2] S. L. Hamlet, R. L. Patterson, S. M. Fleming, L. A. Jones, "Sounds of swallowing following total laryngectomy," Dysphagia Journal Volume 7, Number 3, pp. 160-165, 1992.

[3] D. B. Rendon,, J. L. R. Ojeda, L. F. C. Foix, D. S. Morillo, M. A. Fernandez, "Mapping the Human Body for Vibrations using an Accelerometer," Engineering in Medicine and Biology Society, 2007. EMBS 2007. 29 $9^{\text {th }}$ Annual International Conference of the IEEE, pp 1671-1674, 2007.

[4] J. R. Deller, J. G. Proakis, J. H. L. Hansen, Discrete-Time Processing of Speech Signals, Englewood Cliffs, N.J.: Macmillan, 1993

[5] I. R. Titze, Principles of Voice Production, Prentice-Hall, Inc, 1994.

[6] H. L. Barney, N. J. Madison, "Unitary Artificial Larynx," United States Patent Office. Patent No; 3072745, 1963.

[7] I. Hocevar-Boltezar, M. Zargi, "Communication after laryngectomy," Radiology and Oncology, 35(4): 249-54, 2001

[8] M. Nolan, E. Burke, F. Duignan, "Accelerometer based measurement of body movement for communication, play and creative expression," eMBEC 2008, $4^{\text {th }}$ European Congress for Medical and Biomedical Engineering, 2008

[9] H. Gray, Anatomy of the Human Body, $20^{\text {th }}$ Edition. Lea \& Febiger, Philadelphia, 1918. 